DOI: $10.2478 /$ ausfm-2020-0003

\title{
Arrested and Arresting: Intermedial Images and the Self-Reflexive Spectator of Contemporary Cinema
}

\author{
Hajnal Király \\ Sapientia Hungarian University of Transylvania (Cluj Napoca, Romania) \\ E-mail: hajnal.kiraly@gmail.com
}

\begin{abstract}
The paper departs from the assumption that while the analysis of the systematic effect that popular cinema (genres like melodrama, horror or action movies) has on its spectators has been largely discussed by film theorists, little has been written on the affective dimensions of arthouse cinema. The lasting effect of visually compelling films on the individual spectator's emotions has been addressed only sporadically by cognitive film theory, film phenomenology and aesthetics. Therefore, the author proposes to bring together terms and concepts from different discourses (film and literary theory, intermediality studies and empirical psychological research of the literary effect) in order to elucidate how intermedial, painterly references in midcult and arthouse films mobilize the associative dimensions of film viewing and may have an impact on spectatorial selfreflexion and emotional growth. Moreover, films that rely on the associative power of still(ed) images, painterly references bring into play the personal and cultural experiences of the viewer. As such, they can be effectively used in professional and cultural sensitivization.
\end{abstract}

Keywords: arresting image, self-reflexion, intermediality, stillness, painterly reference, professional sensitivization.

Classical, structuralist and poststructuralist aesthetics of visual arts have always been preoccupied to some extent with the factors contributing to the impact of the image on its spectator, calling them, in turns, "the pregnant moment" of the painting (Lessing in his Laokoön, 1984[1766]), "the punctum" or the "third meaning” of the photograph and film (Roland Barthes in Camera Lucida, 1982, and in The Third Meaning, 1975), or "images in-between" (Bellour 2012) without, however, explicitly raising the issue of individual response to certain - unusual, uncanny, disturbing - images. Similarly, in cognitive film theory, which focuses on 
the cognition-emotion correlation of film-viewing processes and on psychosemiotic interpretation, narrative and genre-centred approach remains dominant, with less focus on emotional responses to formal, aesthetic aspects of cinematic expression and more specifically the impact of images carrying meanings that exceed narrative comprehension (Bordwell 1985 and 1989, Branigan 1992, Caroll 1988, Plantinga and Smith 1999). Film phenomenology relates to the topic of the spectator's emotional response with the introduction of core notions such as embodiment and affect. Scholars of this theoretical paradigm argue that when viewing films feelings and sensations are not only cognitively evoked by the spectator, but are embodied as affects. However, despite a rather large bibliography tackling this subject (for example, Grodal, 1999, Carroll 1988, Plantinga and Smith 1999, Tan 1999, Smith 2003) very little has been written on the individual spectator's state of mind, emotional wellbeing beyond the description of the mechanism of embodiment during the actual film viewing. Starting from the 90s, empirical studies of film, reuniting cognitive film theorists and psychologists, sociologists or neuro-scientists have been busy staging and testing the theses formulated by cognitive theorists of film. These researches involving both quantitative and qualitative methods focused mainly on the spectatorial "meaning making" of film narrative and style, and to a lesser extent on the emotional involvement of the individual spectator (Tan 1996; 2013a; 2013b, Reinhard and Olson 2016). ${ }^{1}$

This essay departs from the assumption that both cognitive and phenomenological film theory has dealt only marginally with film as a possible means for individual self-reflexion and emotional growth. ${ }^{2}$ As Margrethe Bruun Vaage argues, cognitive film theory is still preoccupied with general and typical spectatorial or "audience" responses, defined by Ed Tan as "a systematics of the emotions evoked by films" (Tan 1996, Bruun Vaage 2009). Individually and culturally different responses to film seem to lie beyond the scopes of cognitive film theory. From this theoretical paradigm, it is Torben Grodal getting probably the closest to the phenomenon of subjective response not only to film narrative but also to isolated, powerful film images. As he argues, "the simplest way of evoking a subjective feeling is by

1 In Hungarian context, an issue of Metropolis (2014, no. 1) was dedicated to empirical film studies, authored, among others, by Katalin Bálint, Edina Fecskó, András Bálint Kovács and Orsolya Papp-Zipernovszky. Only recently, in the past few years can be detected a preoccupation with the qualitative research of the spectatorial experience, the relevance of the socio-cultural background and with the role of foregrounding in identification, empathy or sympathy.

2 An exception constitutes Vivian Sobchack's rather anecdotic account of her own leg amputation in the context of spectatorial embodiment, meaning-making and functioning as a kind of "selftherapy," (2004) or Laura U. Marks's interpretation of the culturally determined role of haptic images activating a sensual memory that serves identity quest in non-mainstream films (2000). 
showing images, which only elicit a very limited amount of propositions and which have no links to some concerns of some protagonists. The viewer will quickly make all the cued propositions, and if the sequence goes on beyond the time when all possibilities or making propositions are depleted, the mind will shift into a subjective mode" (Grodal 2000, 90).

Looking for a theoretical, conceptual framework for the persisting emotional and individual effect of disturbing images that multiply the interpretations of a narrative, we can find a similar preoccupation in Barbara Klinger's essay on evocative cinematic images that she calls "arresting images," (2006) and in Margrethe Bruun Vaage's critical writing on cognitive film theory that avoids dealing with the idiosyncratic emotional effect of cinema on its spectator (2009). Instead, Bruun Vaage proposes that film studies apply the findings of empirical literary studies regarding the power of the unfamiliar leading to self-reflexion and self-modifying realizations of the beholder, largely researched by Canadians Don Kuiken and David Miall.

In what follows, I propose to contribute to this rather marginal discourse on the individual emotional impact of certain film images by focusing on a special group of arresting images: pictorial, intermedial images and arrested, still(ed) images, images "in-between," working out a dialogue, as Raymond Bellour formulates "between the movement of the camera and the freezing of the still image, between the present and the past, inside and outside, front and back" $(2012,15)$. As he elaborates, these images in-between "affect the time, the body-soul and the position of the body-gaze, which all find themselves associated with the force that could produce them, or that could at least attest to their visibility: the time between the still and the moving image" (Bellour 2012, 15). Intriguingly, Bellour does not expand on this effect on the body-soul and his reflexive spectator seems to be more concerned with what she/ he sees rather than what she/he feels. In this regard, as Bruun Vaage also suggests, the findings of the empirical research of the reader-response theory, ${ }^{3}$ represented most prominently by the Kuiken-Miall duo, and bringing evidence of the so-called "self-modifying feeling" triggered by aesthetic foregrounding, can establish a link between reflexive and self-reflexive spectator (Miall and Kuiken 2002, 268-69). I will illustrate my arguments with examples that either thematize the emotional effect an image/painting can have on its spectator (the case of Tom Hooper's The

3 This is represented also by Wolfgang Iser, Norman Holland, Hans-Robert Jauss, Roland Barthes, Stanley Fish and Louise Rosenblatt. The main characteristic of this approach is individualism, as it focuses on the transaction between the text's inferred meaning and the reader's subjective response (see transactional theory, represented by Iser and Rosenblatt), on stylistics that works only if subjectively interpreted (Stanley Fish), on the subjective motives of the reader (Norman Holland) and the role of "interpretive community of minds" (Stanley Fish). 
Danish Girl, 2016), or exemplify the complex intertextual web of associations of an arresting still(ed) or painterly image, associations that prompt self-reflexion (the case of Jane Campion's The Piano, 1994, Martin Koolhoven's Brimstone, 2017, Guillermo del Toro's The Shape of Water, 2016 and Andrey Zvyagintsev's Loveless, 2017). The case study at the end of this article exemplifies the role of defamiliarizing painterly references in films, as tools of professional and cultural sensitivization in the training of health professionals.

\section{Arresting and Selfing Images}

The opening images of The Danish Girl, a film based on the true story of Danish artists Lili Elbe (one of the first recipients of transsexual surgery) and Gerda Wegener, show a landscape with a group of leafless trees emanating solitude and melancholia. The first scene of the film departs from the arresting painted image of this landscape, as contemplated by artist Gerda Wegener at the opening event of a gallery exhibition of her husband's works. She is visibly lost in the contemplation of this painting representing something she does not know, something about her husband that she, in a confusing way, feels, but cannot name. The landscape turns back at the end of the film, when, after the death of her husband Einar (who became Lili Elbe and whom she had supported all along in his painful struggle to change his sexual identity), she visits the place depicted in the painting. The return to the initial scene of the film, as a kind of re-framing, appears as a narrative, structural tool closing a psychological process launched with the first shot: a suspicion becoming certitude and finally turning into acceptance and supporting behaviour. I argue that the first scene models not only the position of a pensive spectator who is extracted, isolated from her fictional context by an intermedial image that, as Raymond Bellour puts it, pulls her "out of this imprecise, yet pregnant force: the ordinary imaginary of the cinema" (Bellour 2012, 96). The "mise en scene," the gallery, and the point-ofview shot thematize, beyond "the effects of suspension, freezing, reflexivity, effects that enable the spectator to reflect on what he is seeing" (Bellour 2012, 96) also what she feels. The "arresting" painting launches confusing emotions that later in the film will be voiced as tantalizing questions about own needs in a relationship, the possession of the loved one, the limits of sacrifice, acceptance of the other, and ultimately the capacity of unconditional love.

Although there are other aspects of a film that can trigger self-reflexive, idiosyncratic response - such as the identification with a character, intense emotional scenes, representations of changed states of mind -, I will mainly focus 
on painterly references through framing, composition, lights or colours, or simply images that slow down, open up the narrative, suspend time and linger with us long after watching the film.

Besides the aforementioned individual reference, in The Danish Girl the reenactment of the intermedial gesture of a pose in a painting stirs intense emotional and bodily reaction in the protagonist, prompting his desperate quest for a new sexual identity. The unexpected emotional reaction of Einar sitting as a female model for a painting executed by his wife creates a tension, a confusion in the spectator as well that will escalate along the plot [Figs. 1-2]. Paintings as arresting images and the very act of painting participate organically in the constant selfreflexion and identity quest of the male protagonist, guiding, at the same time, the spectator's attitude towards otherness.

Barbara Klinger's main example of arresting image is the last image from Jane Campion's The Piano, an underwater shot showing Ada, the female protagonist floating in the infinite blue of the sea, accompanied by the puzzling words of the poet Thomas Hood: "There is a silence where hath been no sound. / There is a silence where no sound hath been, / in the cold grave under the deep, deep sea." This closing image corresponds to Bellour's account of the image in-between stillness and movement, a silent "freeze in the frame" connected to an exceptional existential moment, in this case a secretly desired death. As Klinger confesses, this enigmatic image with a blurred meaning has hunted her and prompted her to examine her own emotions and, entering a web of further associations (Hitchcock's Rebecca, 1941 and John Guillermin's King Kong, 1976, among others), helped her to reconsider her subjective implication in a quest for a liberated version of a feminine self (Klinger 2006, 40).

The highly associative power of this arresting image from The Piano is epitomized by its almost identical surfacing, after twenty years, in another Victorian drama with strong undertones of psychological horror, Martin Kolhooven's Brimstone. The image occupies the same position in the narrative, as it appears at its closure and is accompanied by a female voiceover, that of the daughter of the woman in the water. "As life progresses, images blur. Are they remains of memory? Some of them true, some of them false. I remember her well. She was a warrior. In the old century you had to be in order to survive." It is as if Ada's fantasy is coming true, as Liz, the mute female protagonist, a fugitive from her abusive father, deliberately chooses death by water, with an ultimate gesture of freedom, instead of being executed by her male oppressors. Her underwater smile, disturbing as it is, launches a mini-archaeology of memory involving not only The Piano, but also Caravaggio's Medusa, described 
by Thomas Mitchell as a paralysing spectacle addressing the enemy (Mitchell 1995, 176). [Figs. 3-4.] According to Freud, it also stands for the female genitals and sexuality, an apotropaic, or monstrous image addressing a patriarchal order in crisis (Mitchell 1995, 176).

The liberating monstrosity of female sexuality appears in a similar closing scene in a third example of this associative web, The Shape of Water, a romantic monsterphantasy film telling the love story between a humanoid monster from a research laboratory and a mute cleaner: after being chased and shot into the water, we see them embracing underwater. This time a male voiceover accompanies the image, quoting from Persian poet Hakim Sanai, words that again leave us clueless and linger with us, stirring feelings that are either completely new or just have never been experienced in the form provided by the film: "Unable to perceive the shape of You / I find You all around me / Your presence fills my eyes with Your love / It humbles my heart, / For You are everywhere."

According to Barbara Klinger, "arresting images" occur "when a film stops to contemplate an exquisitely composed, significantly evocative and/or uncanny image. The forward motion of the narrative slows down or temporarily halts, allowing this spectacle to capture fully our attention. [...] The exact meaning of the arresting image is unclear; it is at once visually stirring and interpretively opaque. [...] Just as it forestalls easy interpretation, its emotional effects are both intricate and obscure" (Klinger 2006, 24). In her effort to explain its emotional impact, Klinger defines arresting image as a site of lingering affective power and uncertain meaning, strong, ambiguous, memorable, associative, with an unusual temporal status: situated outside of time (fantasy, dream) and serving as a focal point for emotions, it activates a web of associations (personal and cultural experiences, the spectator's storehouse of images). This image is regressive: it goes back to personal and cultural mother lode of images, instigates a mini-archaeology of memory (of other images) and as a moment of intense contemplation, it defamiliarizes its contents. Klinger also speaks about a collusion between autobiography and film when facing an arresting image, revealing the personal as "a strangely composite construction" (2006, 41).

To further elucidate the phenomenon of individual response to arresting images, Margrethe Bruun Vaage proposes the conceptual framework of the empirical research conducted by Canadians David Miall and Don Kuiken. They differentiate between narrative and aesthetic feelings and as they argue, the unconventional flow of feeling experienced at times in literary reception can prompt unexpected realizations. According to them, reflecting on an emotion can trigger cognitive 
transformations. "What is realized (recognized) also may become real-ized (made real) and carried forward as a changed understanding of the reader's own life-world. We propose that this process of real-ization through literary reading involves a form of reflexivity that is itself figurative. We also suggest that the feelings integral to such figurative real-ization be called self-modifying feelings to differentiate them from evaluative feelings toward the text as a whole; aesthetic feelings in response to stylistic variations; and narrative feelings in reaction to the setting, characters, and events" (Miall and Kuiken 2002, 268-269).

As Miall and Kuiken point out, while not identical with them, these selfmodifying feelings are greatly produced by aesthetic feelings resulting from unsettling, defamiliarizing images, that in case of intermedial references seem to lie outside the narrative, as if meant to reframe our emotional experience stirred by the story. The ending images of Andrey Zvyagintsev's Loveless exemplify this mechanism plastically. It is a dramatic story about the devastating effects of a painful divorce, which follows the desperate quest for a missing child - fugitive due to strong emotional neglect - exposing the spectator to strong, contradictory feelings; then the narration comes to a halt: the boy is found dead and an unidentified gaze is moving around in the former home of the broken family, at that moment empty and under refurbishment. The presence of this gaze is unsettling, reminiscent of ghost stories: it slowly leaves behind the workers in the apartment and slides through the window after framing the view behind it as a silent painting reminding of Pieter Brueghel the Elder's Winter Landscape with a Bird Trap (1565), probably one of the most well-known paintings in the world [Figs. 5-6]. The palette of greys, blues and pale greens is offset by the colourful costumes worn by many of the participants, the overlapping branches of the trees and bushes, serve to create a wonderful decorative effect. This gesture of leaving behind a scene contaminated with so much pain and betrayal, and stepping into another, apparently peaceful painterly composition reframes our numbness caused by the shock of this outcome as a kind of acceptance of the fragility of life. In fact, it has often been suggested that the Winter Landscape with a Bird Trap, for all its realism, also contains an underlying message alluding to the precariousness of life. In one of his engravings of Winter - Ice Skating before St. George's Gate, Antwerp, Pieter Bruegel the Elder added the inscription: Lubricitas Vitæ Humanæ. La lubricité de la vie humaine. De slibberachtigeyt van's Menschen Leven ("The Precariousness of Human Life") referring to the ways in which people find themselves slipping and sliding through a life whose existence is more slippery and fragile than ice itself. In Loveless, the modifying of a first feeling, that of terror, by a second, that of acceptance with the intermediation of a painterly reference 
can be conceived as a form of catharsis, understood by Kuiken and Miall not as purification, but rather as a clarification of the spectator's emotional experience (Miall and Kuiken 2002, 234). In line with Margrethe Bruun Vaage's argumentation, the aesthetic feelings stirred by the intermedial reference in Loveless enhance feeling-guided boundary crossing (Bruun Vaage 2009, 226).

As the examples and analyses above prove, intermedial images and images in-between movement and stillness, due to their highly associative potential are susceptible to prompt self-reflexion and the clarification of the spectator's emotional experiences. The issue of idiosyncratic emotional response to arresting images may seem a slippery ground for research, but there is already evidence of both individual and group benefits of their cultural, associative value, with a relevant therapeutic and educational potential to be exploited. The following case study presents an excerpt from a training programme for health professionals using films, with focus on the clinical representations of the sick body and its intermedial image as tool for cultural and professional sensitivization.

\section{The Intermedial Image as Educational Tool}

The optional course Representations of the Body and Healthcare in Contemporary European Cinema was held in two consecutive semesters in 2019 at the Faculty of Health Sciences, University of Szeged, Hungary. It proposed a cultural theoretical approach to the body representations in contemporary European cinema through ten representative films from all over Europe: Germany, France, the United Kingdom, Hungary, Romania, Italy, Greece and Spain. Special attention was given to the body seen in a clinical setting and to the clinical gaze, both symptomatic of current European social, cultural and institutional relationships. Relying on anthropological, cultural and psychoanalytical discourses, this practical course focused on the ways the social body is reflected in the individual body, this latter often becoming a figure of a deep identity and existential crisis. The debated topics included the body as site of sexual identity, the cinematic representation of the female amputee and her social rehabilitation, the clinical gaze as a figure of alienation and distancing, of a hierarchical and patriarchal society, the clinical gaze and Foucault's panopticon model, clinical (self)observation and quest for identity, the clinic and sanatorium as crisis heterotopia in Western culture, body and addiction, as well as the issue of political/institutional loyalty and the morality of health professionals. The educational aims of the course were familiarization with cinematic representations of the (clinical, sick, addicted, sexual, etc.) body, its 
cultural discourses and theoretical concepts, development of the awareness of the interdependence between the individual, physical and social body, training of the ability to recognize the figurative representations of the relationship between body and society, of the psychological, institutional implications of bodily symptoms, as well as the training of empathy and moral attitude through group discussions about representative scenes involving health care, patient-health professional relationship and social, cultural taboos of the sexual body.

The course was held in the framework of English-language training of mostly nonEuropean students, future nurses and physiotherapists coming from Middle Eastern, Far-Eastern or African countries: Afghanistan, Pakistan, Iran, India, China, Egypt, Azerbaijan, Nigeria, South Africa and Morocco. Many of the students had only been in Hungary for a relatively short time (up to one year), therefore a careful selection of European arthouse films with a topic related to healthcare in a clinical setting and/or representations of bodies in physical or psychological distress also had as secondary purpose a cultural socialization with European arthouse cinema trends of visual representations of the body, of its European healing institutions, professional networks and hierarchies, as well as with the discourses of the gaze and supervision objectifying the body. The analysed films and topics ${ }^{4}$ served as a framework for ingroup discussions in which own cultural experiences were compared, contrasted and filtered through the culturally determined visual and narrative codes of bodyrepresentations in European arthouse cinema. The discussions revolved around the narrative and visual familiar and unfamilar, the emotional response of the students to these aspects of the films under analysis, clarification of unclear scenes and situations, and had the purpose to help students understand new and demanding professional situations, as well as ethnic, bodily, sexual otherness, and live their emotions related to all this in a safe, guided group context. In-class discussions were completed with a feedback-questionnaire (adapted by me, H. K. from Kuiken and Miall's Literary Response Questionnaire, 1995), focusing on the film-viewing

4 The ten films and topics debated in the course of each semester were the following: The Body under Post-Communist Conditions (Cristi Puiu, The Death of Mister Lazarescu, 2006), The Clinical Gaze in Contemporary Hungarian Cinema (Kornél Mundruczó, Johanna, 2005), The Panopticon Model of the Clinic (Ágnes Kocsis, Adrienn Pál, 2010), Clinical Investigation and Identity Quest (Attila Gigor, The Investigator, 2008), History and Body-Memory (György Pálfi, Taxidermia, 2006), The Public and the Private Body (Christian Petzold, Barbara, 2012), Body and Sexual Identity (Pedro Almodovar, Talk to Her, 2002), Entrapped by Own Body: Narcissism and Addiction (Steve McQueen: Shame, 2011), Rehabilitation of the Amputee (Jacques Audiard, Rust and Bone, 2013), The Sanatorium as Social Allegory (Yorgos Lanthimos, The Lobster, 2015), The Sanatorium and the Western Obsession with Youth (Paolo Sorrentino, Youth, 2015), and Precarious Bodies: the Sanatorium in the Eastern European Cinema (Radu Jude, Scarred Hearts, 2016). 
experience: the degree of absorption or alienation (how difficult they found watching the film, with the specification of the difficult aspects), familiar/unfamiliar scenes (with a possibility to explain the reason of it), degree of identification with the main character, and a further question referred to the effect of slowness (as a shared characteristic of all the films under analysis) on the viewer.

The responses to the questionnaire revealed the difficulty of "watching the pain of others," for example in the scenes draining the puce from the vertebrae of Emanuel with a big needle in Scarred Hearts. Students also reported feeling for him because of being condemned to spend his life horizontally, closed in a cast. At the same time, they have appreciated his coping strategy largely based on poetic writing, verbal expression, play with language, humour and building human relationships, making friends and falling in love with women. Just like in Paolo Sorrentino's Youth (2015), in Scarred Hearts beauty (art and literary writing) becomes the sole remedy for physical and spiritual pain. This idea is reinforced by one of the unusual, highly figurative representations of the above-mentioned medical intervention. This tableau-image, arrested and arresting, is a straightforward reference to Rembrandt's The Anatomy Lesson of Dr. Tulp (1632), and just like its original, is rich in coded, figurative significations regarding both the represented medical attitude and the spectatorial meaning making [Figs. 7-8]. It models a distancing, objectifying attitude towards the body of a patient still alive: all the participants of the scene are focusing on the critical spot of his body, pointed out by the jovial doctor who is unable to support his patients in terms of giving them a continuous, realistic, up-to-date diagnosis. This avoidant attitude, characteristic of the whole staff is relying on promises and humour, systematically substituting the person with the body. Empathy and sympathy are represented by current and former patients of the sanatorium who are able to feel the distress of the other. Some of them come too close and their sympathy is mistaken by Emanuel for love (the case of his affair with Solange). For the students who had already known this painting, the unsettling effect was double, familiar and unfamiliar at the same time: the role of the tableau-shot arresting the flow of action and the spectator's attention in the case of this particular film instigated a new meaning-making. While throughout the guided discussion students identified this aesthetic framing as corresponding to the main character's own sublimatory strategy, this shot also actualized the message of Rembrandt's painting: "see the person in the medical scene!"

An interpretation of this painting - although in a different context - appears in Christian Petzold's film Barbara, set in a remote clinic of socialist East Germany. The reproduction of the painting in the office of the chief physician André (a doctor 
recently relocated to this hospital due to disciplinary reasons) serves as a mediator in the communication between him and Barbara. As Wim Staat argues in his essay on Petzold's melodramas, in this film artefacts (painting and literature) have the role to provide coded messages under the conditions of constant supervision and a politically generated atmosphere of mistrust (Staat 2016). Barbara immediately realizes that there is a mistake in the painting (the wrong hand is being dissected), a mistake considered by André as deliberate, since none of the characters in the painting - the disciples of dr. Tulp - observe it because they are focusing on the anatomy book in front of them, on theory and rules instead of the body itself. In this scene, which is also modelling spectatorial meaning-making, Rembrandt's message "Look at the body!" or "Look at the patient!" translates as "Look at me!" - as an invitation for Barbara to trust André, her colleague, despite the political context and its rules. [Figs. 9-10.]

In both Scarred Hearts and Barbara, the intermedial tableau-shot and the reproduction on the wall function as arresting images that activate a web of personal and cultural associations in the spectator and instigate a mini-archaeology of memory of other images by defamiliarizing its contents (this is not only an anatomy lesson). As such, it can be regarded as a figuration of all visual representations and interpretations of the body and healthcare in the contemporary European arthouse films discussed in the course with the educational purpose of sensitivization, that is, of training the ability to see the story beyond the case and the person beyond the body. The emotional responses (of fear, repulsion, puzzlement, embarrassment, pity, sympathy or empathy) could be lived in a safe framework provided by the fictional story, visual mediation and figuration, as well as the open discussion in the educational context of the seminar.

The professional sensitivization programme described above relied on the elementary power of visual storytelling and figuration, which, due to its highly associative potential, is likely to prompt self-reflexion and the clarification of the spectator's emotional experiences. It made possible for students, future health professionals to experience safely - with the intermediation of arresting images - difficult clinical situations and reflect upon their own feelings of empathy and sympathy, as well as their different cultural stereotypes of the body in distress. As the above presented films and analyses emphasize, these reflections can prompt a web of associations animated by own biography and lead to self-modifying feelings, as well as to a cathartic moment that clarifies initial feelings and motivations. 


\section{References}

Barthes, Roland. 1978. The Third Meaning. In Image, Music, Text. New York: Hill and Wang, 51-68.

Barthes, Roland. 1982. Camera Lucida. Notes on Photography. New York: Hill and Wang.

Bellour, Raymond. 2012. Between-the Images. Zürich: JRPIRingier.

Bordwell, David. 1985. Narration in the Fiction Film. Madison: University of Wisconsin Press.

Bordwell, David. 1989. A Case for Cognitivism. Iris vol. 9: 11-40.

Branigan, Edward. 1992. Narrative Comprehension and Film. London, New York: Routledge.

Bruun Vaage, Margrethe. 2009. Self-Reflexion. Beyond Conventional Fiction Film Engagement. Nordicom Review vol. 30, no. 2: 159-178.

Carroll, Noel. 1988. Mystifying Movies: Fads and Fallacies in Contemporary Film Theory. New York: Columbia University Press.

Grodal, Torben. 1999. Moving Pictures: A New Theory of Film Genres, Feelings, and Cognition. Oxford: Oxford University Press.

Hakemulder, Frank. 2000. The Moral Laboratory: Experiments Examining the Effects of Reading Literature on Social Perception and Moral Self-Concept. Amsterdam, Philadelphia: John Benjamins Publishing Company.

Klinger, Barbara. 2007. The Artfilm, Affect and the Female Viewer. The Piano Revisited. Screen vol. 47, no.1: 19-41.

Lessing, Joachim Gotthold. 1984 [1766]. Laocoön. An Essay on the Limits of Painting and Poetry. London: The Johns Hopkins Press.

Marks, Laura U. 2000. The Skin of the Film. Intercultural Cinema, Embodiment, and the Senses. Durham and London: Duke University Press.

Miall, David S. and Don Kuiken. 1994. Foregrounding, Defamiliarization, and Affect: Response to Literary Stories. Poetics vol. 22, no. 5: 389-407.

Miall, David S. and Don Kuiken. 1995. Aspects of Literary Response: A New Questionnaire. Research in the Teaching of English vol. 29, no. 1: 37-58.

Miall, David S. and Don Kuiken. 2002. A Feeling for Fiction: Becoming What We Behold. Poetics vol. 30, no. 4: 221-241.

Mitchell, J.W. Thomas. 1995. Ekphrasis and the Other. In Picture Theory. Chicago: Chicago University Press, 151-180.

Plantinga, Carl and Greg M. Smith, eds. 1999. Passionate Views: Film, Cognition, and Emotion. Chicago: Johns Hopkins University Press. 
Reinhard, CarrieLynn D. and Cristopher J. Olson. 2016. Making Sense of Cinema. Empirical Studies into Film Spectators and Spectatorship. London, New York: Bloomsbury Academic.

Smith, Greg. 2003. Film Structure and the Emotion System. New York: Cambridge University Press.

Sobchack, Vivien. 2004. Carnal Thoughts. Embodiment and Moving Image Culture. Berkeley and Los Angeles: University of California Press.

Staat, Wim. 2016. Christian Petzold's Melodramas: From Unknown Woman to Reciprocal Unknownness in Phoenix, Wolfsburg, and Barbara. Studies in European Cinema vol. 13, no. 3: 185-199.

Tan, Ed S. 1996. Emotion and the Structure of Narrative Film. Film as an Emotion Machine. Mahwah, NJ: Lawrence Erlbaum.

Tan, Ed. 2013. The Empathic Animal Meets the Inquisitive Animal in the Cinema: Notes on a Psychocinematics of Mind Reading. In Psychocinematics, ed. Arthur P. Shimamura, 337-368. Oxford: Oxford University Press.

Tan, Ed and Gijsbert Diteweg. 2013. Suspense, Predictive Inference, and Emotion in Film Viewing. In Suspense: Conceptualizations, Theoretical Analyses, and Empirical Explorations, eds. Peter Vorderer, Hans Jurgen Wulff and Mike Friedrichsen, 149-188. New York-London: Routledge.

\section{List of Figures}

Figures 1-2. Posing for paintings as decisive act of identity change in The Danish Girl.
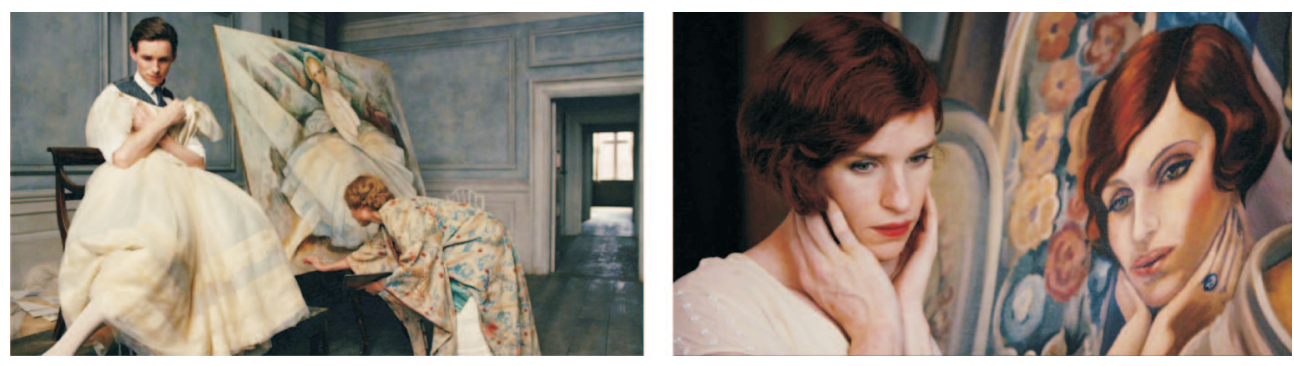
Figures 3-4. Underwater shots evocative of the Medusa head, standing for a female monstrosity fighting male oppression in Victorian dramas The Piano (1994) and Brimstone (2017).
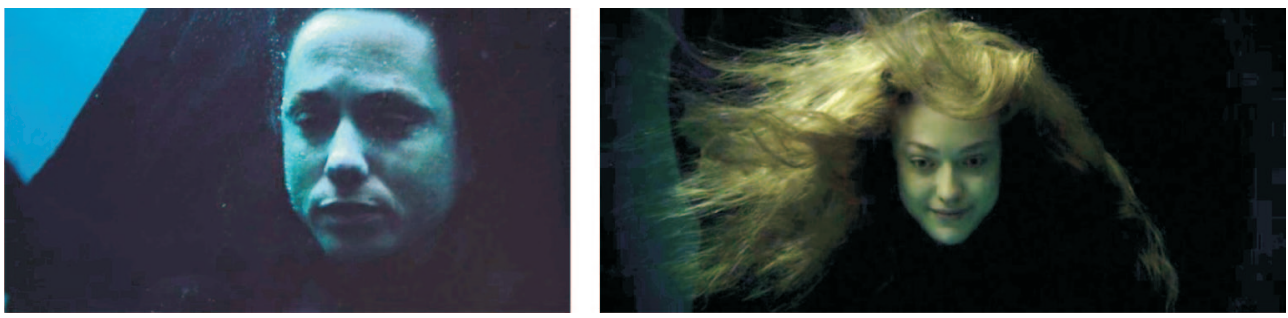

Figures 5-6. The re-framed winter landscape in Loveless as reference to Pieter Brueghel the Elder's Winter Landscape with a Bird Trap, mediating catharsis.
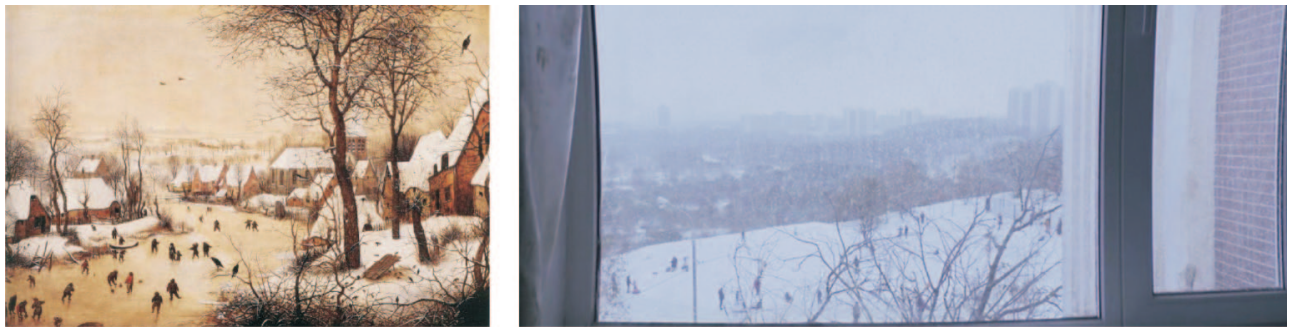

Figures 7-8. Rembrandt's The Anatomy Lesson of Dr. Tulp (1632) and the tableaushot reference to it from Radu Jude's Scarred Hearts (2018) as illustration of a professional attitude and the sublimatory effect of beauty.
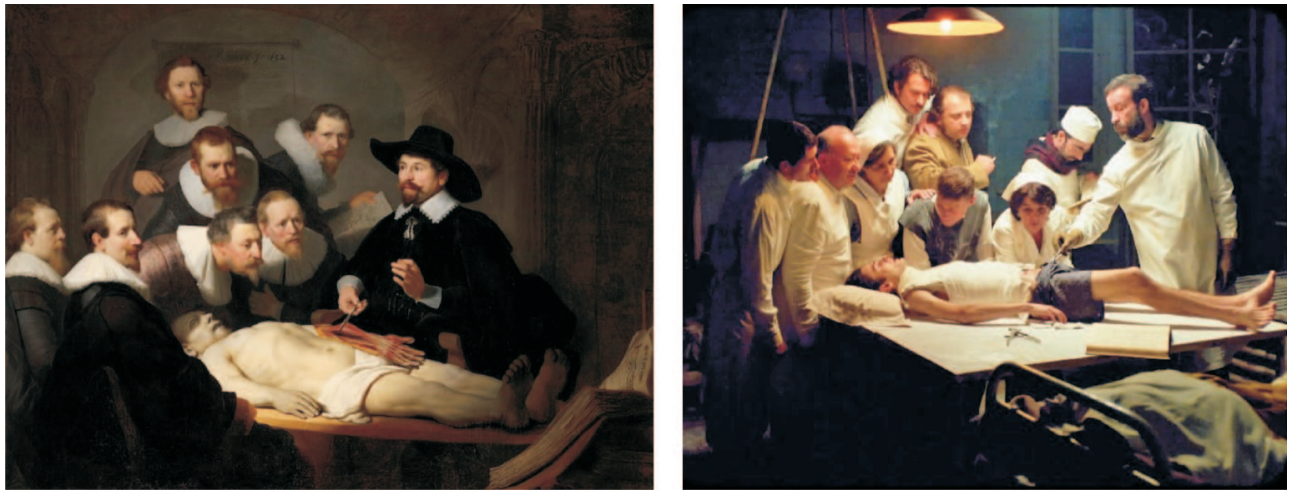
Figures 9-10. Rembrandt's painting as coded message in an oppressing political regime in Christian Petzold's Barbara (2012).
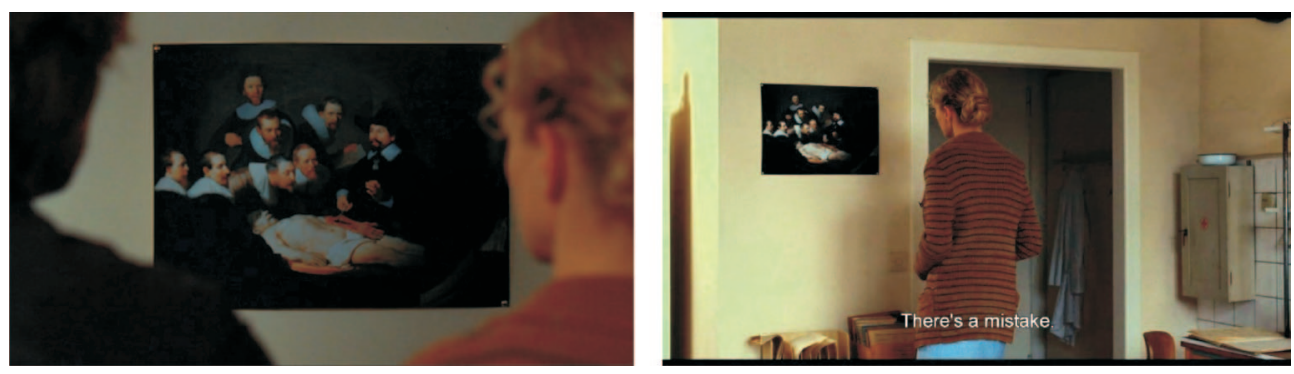